\title{
Short term reproducibility of exercise testing in patients with ST segment elevation and different responses to the dipyridamole test ${ }^{\star}$
}

\author{
EUGENIO PICANO, MICHELE MASINI, FABIO LATTANZI, \\ GERALD A KLASSEN, ALESSANDRO DISTANTE, DANIELE LEVANTESI, \\ PAOLO MARRACCINI, ANTONIO L'ABBATE
}

From the National Research Council, Clinical Physiology Institute, University of Pisa, Pisa, Italy

SUMMARY The short term reproducibility of exercise testing in 25 patients who had exercise induced ST segment elevation without baseline regional asynergy or a previous myocardial infarction, who had different responses to the dipyridamole test, was assessed. The patients performed a dipyridamole echocardiography test and a second exercise stress test. All underwent coronary arteriography. Seventeen patients had transient regional asynergy after dipyridamole (group 1) and either ST segment elevation (14 patients) or depression (three patients); a second group of eight had no asynergy and no electrocardiographic changes (group 2). The repeated exercise stress test was positive in 16 of the 17 patients of group 1 (11 with ST elevation and five with ST depression) and in two patients of group 2 (both had ST depression and one had coronary artery disease). The dipyridamole echocardiography test was positive in 17 of the 19 patients with coronary artery disease and was negative in all six patients without coronary artery disease. The repeated exercise stress test was positive in 17 of the 19 patients with coronary artery disease and in one patient without.

The dipyridamole echocardiography test and a repeated exercise stress test, but not a single exercise stress test, identified coronary artery disease causing exercise induced ST segment elevation.

In patients with effort induced ST segment elevation (without previous myocardial infarction) the dipyridamole echocardiography test may provide information on the underlying coronary structure and possibly the mechanism responsible for this uncommon electrocardiographic pattern on effort. ${ }^{1}$

Dipyridamole is a selective coronary arteriolar vasodilator, and has no known vasoconstrictive effects. ${ }^{23}$ A positive dipyridamole echocardiography test with ST segment elevation is usually associated with severe coronary disease and suggests that fixed coronary lesions are responsible for the effort induced ST segment elevation. ${ }^{1}$ Conversely, when the dipyridamole echocardiography test is negative

Requests for reprints to Dr Eugenio Picano, Istituto di Fisiologia Clinica del CNR, Via Savi 8, 56100 - Pisa, Italy.

*Presented in part at the 59th meeting of the American Heart Association, Dallas, 17-20 November 1986.

Accepted for publication 23 May 1988 for both echocardiographic and electrocardiographic criteria, a functional mechanism (spasm) is most likely to be the cause of ST segment elevation during exercise. ${ }^{145}$

The short term reproducibility of the exercise stress test may be another method of evaluating the underlying structure of the coronary arteries and the pathogenetic mechanism of effort induced ST segment elevation. Serial exercise stress tests in patients with angina that is predominantly caused by fixed lesions consistently demonstrate a fixed threshold, ${ }^{6}$ while predominantly vasospastic angina is characterised by considerable variability of the electrocardiographic findings during repeat exercise stress tests. ${ }^{7-9}$

The aim of this study was to evaluate the short term reproducibility of the exercise stress test in patients with effort induced ST segment elevation and different responses to the dipyridamole echocardiography test. We tested the hypothesis that 
exercise stress tests that were reproducible and had a fixed threshold indicated clinically important coronary stenosis, whereas considerable variability indicated spasm.

\section{Patients and methods}

\section{SELECTION OF PATIENTS}

Twenty five patients (23 men and two women, mean (SD) age 53 (8) years, range 39-67) with exercise induced ST segment elevation without previous myocardial infarction or baseline asynergy at echocardiography or left ventriculography were enrolled in the study. Patients performed a dipyridamole echocardiography test and a repeat exercise stress test; all underwent coronary arteriography and left ventriculography.

Fifteen patients had documented variant angina (characterised by ST segment elevation at rest or after ergometrine provocation). No patient was taking medications.

\section{EXERCISE STRESS TEST}

Patients performed two multistage bicycle ergometer tests, with an initial load of $25 \mathrm{~W}$ and subsequent increases of $25 \mathrm{~W}$ every two minutes. A 12 lead electrocardiogram and systolic and diastolic blood pressures were recorded before exercise and every minute during exercise. The end points of the test were moderately severe chest pain, a diagnostic ST segment shift, maximal age related heart rate, and limiting dyspnoea or fatigue in the absence of ischaemia.

The test was repeated in each patient at a different time the next day: once in the morning between 8 and 11 am and once in the afternoon, between 3 and $6 \mathrm{pm}$.

Electrocardiographic tracings were noted as showing myocardial ischaemia when the ST segment altered its position by $>1.00 \mathrm{~mm} 0.08$ seconds after the J point occurred.

\section{DIPYRIDAMOLE ECHOCARDIOGRAPHY TEST}

Cross sectional echocardiographic and 12 lead electrocardiographic monitoring were performed during a dipyridamole infusion $(0.56 \mathrm{mg} / \mathrm{kg}$ over $4 \mathrm{~min}$ utes).$^{10}$ In patients with a negative result the test was repeated the next day with a higher dose $(0.56 \mathrm{mg} / \mathrm{kg}$ over 4 minutes followed by 4 minutes of no dose and then $0.28 \mathrm{mg} / \mathrm{kg}$ (half of the previous dose) over 2 minutes); the cumulative dose was therefore $0.84 \mathrm{mg} /$ kg over 10 minutes. ${ }^{11}$ The test was considered positive if there was transient asynergy of contraction (hypokinesia, akinesia, or dyskinesia) that had not been present during the baseline examination. ${ }^{1011}$

Aminophylline (240 mg) was available, if needed, to reverse the effects of dipyridamole. During the procedure, the blood pressure and the electrocardiogram were recorded each minute. The electrocardiographic criteria for ischaemia during this test were the same as those used during the exercise stress test. Cross sectional echocardiogramswere continuously recorded during and up to $20 \frac{\overline{5}}{5}$. minutes after dipyridamole administration.

We used a commercially available wide angle phased array imaging system (Hewlett Packards 77020). In the baseline studies whenever it was $\overrightarrow{0}$ possible we imaged all the standard echocardio-graphic views. During the test new areas of abnormajw wall motion were identified on multiple views bys rapidly moving the ultrasound transducer through? various positions.

According to a generally accepted qualitative analysis, the wall motion was graded as: hyperkinetic ${ }_{2}^{\infty}$ normal, hypokinetic, akinetic, and dyskinetic. ${ }^{10}$ Twoo independent observers analysed the videotapes? When there was disagreement about the results 20 third observer reviewed the study and decided the issue. None of the observers had access to the results: of the angiographic or exercise stress tests before they_ graded the videotape. The dipyridamole test waso repeated a second time on a different day.

\section{ANGIOGRAPHIC STUDY}

Patients underwent biplane left ventriculography and selective right and left coronary arteriography by either the Judkins' or the Sones' technique. Multiple views of each coronary artery were obtained, includ $-\frac{1}{7}$ ing craniocaudal views. Two independent observers assessed degrees of stenosis in the major coronary arteries shown by the angiograms. A vessel waș considered to show significant obstruction if its diameter was narrowed by $>70 \%$. The severity of stenosis was estimated in the projection where if appeared to be most severe.

All the observers were unaware of echocardio graphic and electrocardiographic data.

\section{STATISTICAL ANALYSIS}

The statistical significance was evaluated by the $\chi_{0}^{?}$ test. A p value $<0.05$ was considered to be statis tically significant.

\section{Results}

The table shows the results of the dipyridamolo echocardiography test, of both exercise stress tests, and of coronary arteriography.

\section{DIPYRIDAMOLE ECHOCARDIOGRAPHY TEST}

In the 50 analysed tests (two for each patient), the evaluation by two observers was consistent in 46 an 
Table Results of dipyridamole echocardiography test, both exercise stress tests, and coronary angiography

\begin{tabular}{|c|c|c|c|c|c|c|c|c|c|}
\hline \multirow[b]{2}{*}{ Patient } & \multirow[b]{2}{*}{ Age/sex } & \multicolumn{2}{|l|}{ Dipyridamole test } & \multicolumn{3}{|l|}{ Exercise stress tests } & \multicolumn{3}{|c|}{$\begin{array}{l}\text { Coronary angiography } \\
\text { (\% stenosis) }\end{array}$} \\
\hline & & $E C G$ & Asynergy & $E C G$ & 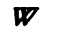 & $\boldsymbol{R P P}$ & $L A D$ & $L C X$ & $R C A$ \\
\hline 1 & $56 M$ & $\uparrow \mathbf{V}-6$ & Septal-lateral & $\begin{array}{l}\text { TV2-6 } \\
\text { TV2-6 }\end{array}$ & $\begin{array}{l}75 \\
75\end{array}$ & $\begin{array}{l}176 \\
179\end{array}$ & 90 & 0 & 50 \\
\hline 2 & $66 \mathrm{M}$ & $\uparrow V 4-6$ & Septal & $\begin{array}{l}\text { tv } 4-6 \\
\text { v4 }\end{array}$ & $\begin{array}{l}75 \\
75\end{array}$ & $\begin{array}{l}165 \\
175\end{array}$ & 100 & 0 & .40 \\
\hline 3 & $57 \mathrm{M}$ & $\uparrow D 3$, aVF & Posterior & $\begin{array}{l}\text { tD3 } \\
\text { NC }\end{array}$ & $\begin{array}{l}100 \\
100\end{array}$ & $\begin{array}{l}224 \\
214\end{array}$ & $\mathbf{0}$ & 0 & 90 \\
\hline 4 & $60 M$ & $\uparrow \mathrm{D} 1, \mathrm{aVL}, \mathrm{V} 2-5$ & Lateral-apical & $\begin{array}{l}\mathrm{D} 1, \mathrm{aVL}, \mathrm{V} 2-5 \\
\mathrm{D} 1, \mathrm{aVL}, \mathrm{V} 2-5\end{array}$ & $\begin{array}{l}50 \\
50\end{array}$ & $\begin{array}{l}197 \\
186\end{array}$ & 90 & 0 & 0 \\
\hline 5 & $63 \mathrm{M}$ & $\uparrow \mathbf{V} 2-3$ & Septal & $\begin{array}{l}v 2-3 \\
+V 2-3\end{array}$ & 100 & $\begin{array}{l}288 \\
274\end{array}$ & 90 & 0 & 0 \\
\hline 6 & $54 M$ & $\uparrow D 1, a V L, V 4-6$ & Lateral & $\begin{array}{l}V 4-6 \\
\text { V }-6\end{array}$ & $\begin{array}{l}100 \\
125\end{array}$ & 235 & 100 & 100 & 0 \\
\hline 7 & $59 M$ & $\uparrow \mathrm{D} 3, \mathbf{a V F}$ & Posterior & $\begin{array}{l}\text { D3, aVF } \\
\text { D3, aVF }\end{array}$ & $\begin{array}{l}75 \\
75\end{array}$ & $\begin{array}{l}204 \\
193\end{array}$ & 90 & 40 & 100 \\
\hline 8 & $67 M$ & $\downarrow$ V4-6, D2-3, aVF & Posterior-lateral & aV2-3, aVF, V4-6 & $\begin{array}{l}50 \\
50\end{array}$ & $\begin{array}{l}214 \\
211\end{array}$ & 0 & 100 & 75 \\
\hline 9 & $46 \mathrm{~F}$ & IV4-6 & Septal & tv2 & $\begin{array}{r}100 \\
75\end{array}$ & $\begin{array}{l}190 \\
175\end{array}$ & 90 & 0 & 0 \\
\hline 10 & $42 M$ & $\uparrow \mathrm{D} 1, \mathrm{aVL}, \mathrm{V} 2-4$ & Lateral-apical & $\begin{array}{l}\text { faVL, V2-6 } \\
\text { faVL, V2 }\end{array}$ & $\begin{array}{l}75 \\
50\end{array}$ & $\begin{array}{l}280 \\
216\end{array}$ & 75 & 0 & 100 \\
\hline 11 & $58 \mathrm{M}$ & $\uparrow \mathbf{V 2}$ & Septal & $\begin{array}{l}\text { fV2 } \\
\text { V2 }\end{array}$ & $\begin{array}{l}50 \\
25\end{array}$ & $\begin{array}{l}165 \\
153\end{array}$ & 100 & 0 & $\mathbf{0}$ \\
\hline 12 & 52 F & $\uparrow \mathrm{D} 2-3, \mathrm{aVF}$ & Posterior & $\begin{array}{l}\text { D2-3, aVF } \\
\text { V4 }\end{array}$ & $\begin{array}{l}25 \\
50\end{array}$ & $\begin{array}{l}170 \\
180\end{array}$ & 25 & 90 & 0 \\
\hline 13 & $50 \mathrm{M}$ & $\uparrow \mathrm{V2}, \mathrm{aVL}$ & Septal-apical & $\begin{array}{l}\text { T2 } \\
\text { Y2 }\end{array}$ & $\begin{array}{l}100 \\
100\end{array}$ & $\begin{array}{l}195 \\
160\end{array}$ & 90 & 0 & 50 \\
\hline 14 & $49 M$ & †aVL & Septal & tavL & $\begin{array}{l}50 \\
75\end{array}$ & 165 & 100 & 0 & 40 \\
\hline 15 & $47 M$ & $\downarrow$ V6 & Apical & $\begin{array}{l}\text { TaVL, V6 } \\
\text { TaVL, V6 }\end{array}$ & $\begin{array}{l}75 \\
75\end{array}$ & $\begin{array}{l}182 \\
168\end{array}$ & 90 & 0 & 0 \\
\hline 16 & $53 \mathrm{M}$ & $\uparrow \mathbf{V 4}$ & Septal-lateral & †V3-5 & $\begin{array}{l}50 \\
50\end{array}$ & $\begin{array}{l}150 \\
161\end{array}$ & 90 & 0 & 0 \\
\hline 17 & $46 M$ & †aVL & Septal-apical & faVL & $\begin{array}{l}25 \\
50\end{array}$ & $\begin{array}{l}239 \\
248\end{array}$ & 100 & 0 & 0 \\
\hline 18 & $49 M$ & NC & No & & $\begin{array}{r}50 \\
100\end{array}$ & $\begin{array}{l}104 \\
208\end{array}$ & 0 & 0 & 0 \\
\hline 19 & $43 M$ & NC & No & $\begin{array}{l}\text { †V2^ } \\
\text { NC }\end{array}$ & $\begin{array}{l}100 \\
100\end{array}$ & $\begin{array}{l}315 \\
322\end{array}$ & 75 & $\mathbf{0}$ & $\mathbf{0}$ \\
\hline 20 & $49 M$ & NC & No & $\prod_{\mathrm{V} 4}^{\mathrm{D} 1, \mathrm{aVL}}$ & $\begin{array}{l}25 \\
75\end{array}$ & $\begin{array}{l}103 \\
224\end{array}$ & $\mathbf{0}$ & 90 & 75 \\
\hline 21 & $46 M$ & NC & No & $\begin{array}{l}\text { IV2-3* } \\
\text { NC }\end{array}$ & $\begin{array}{l}75 \\
75\end{array}$ & $\begin{array}{l}276 \\
280\end{array}$ & 50 & 0 & 0 \\
\hline 22 & $64 M$ & NC & No & $\begin{array}{l}\text { TD2-3, aVF } \\
\text { NC }\end{array}$ & $\begin{array}{l}50 \\
75\end{array}$ & $\begin{array}{l}162 \\
199\end{array}$ & 0 & 0 & 40 \\
\hline 23 & $60 M$ & NC & No & faVL & $\begin{array}{r}75 \\
100\end{array}$ & $\begin{array}{l}210 \\
228\end{array}$ & 0 & 0 & 0 \\
\hline 24 & $51 \mathrm{M}$ & NC & No & $\begin{array}{l}\text { TD1, aVL } \\
\text { NC }\end{array}$ & $\begin{array}{l}100 \\
100\end{array}$ & $\begin{array}{l}163 \\
179\end{array}$ & 0 & 25 & 0 \\
\hline 25 & $39 \mathrm{M}$ & NC & No & †V2-6 & $\begin{array}{r}50 \\
100\end{array}$ & $\begin{array}{r}82 \\
270\end{array}$ & 50 & 0 & 0 \\
\hline
\end{tabular}

*After the end of exercise.

LAD, left anterior descending coronary artery; LCX, left circumflex coronary artery; NC, no changes; RCA, right coronary artery; RPP, rate pressure product.

†ST segment depression; $\uparrow$ ST segment elevation; lateral, anterolateral wall; posterior, inferoposterior wall; septal, ventricular septum.

different in four, when the opinion of a third observer was the deciding factor.

This test identified two groups: group 1 (17 patients) with dipyridamole induced asynergy and either ST segment elevation (14 patients, figure) or depression (three patients); and group 2 (eight patients) in which dipyridamole did not induce asynergy that was detectable by either echocardiographic or electrocardiographic criteria.

The echocardiographic and electrocardiographic findings were the same in both tests. Coronary arteriography showed clinically significant coronary artery disease in all $17(100 \%)$ patients in group 1 and in two $(25 \%)$ of the eight patients of group 2 (p < 0.01). The dipyridamole echocardiography test identified coronary artery disease in $92 \%$ of the patients who were positive by angiography.

\section{BXERCISE STRESS TEST}

The repeated exercise stress test showed diagnostic ST segment changes in 16 of 17 patients in group 1 (11 had ST segment elevation and five had ST 


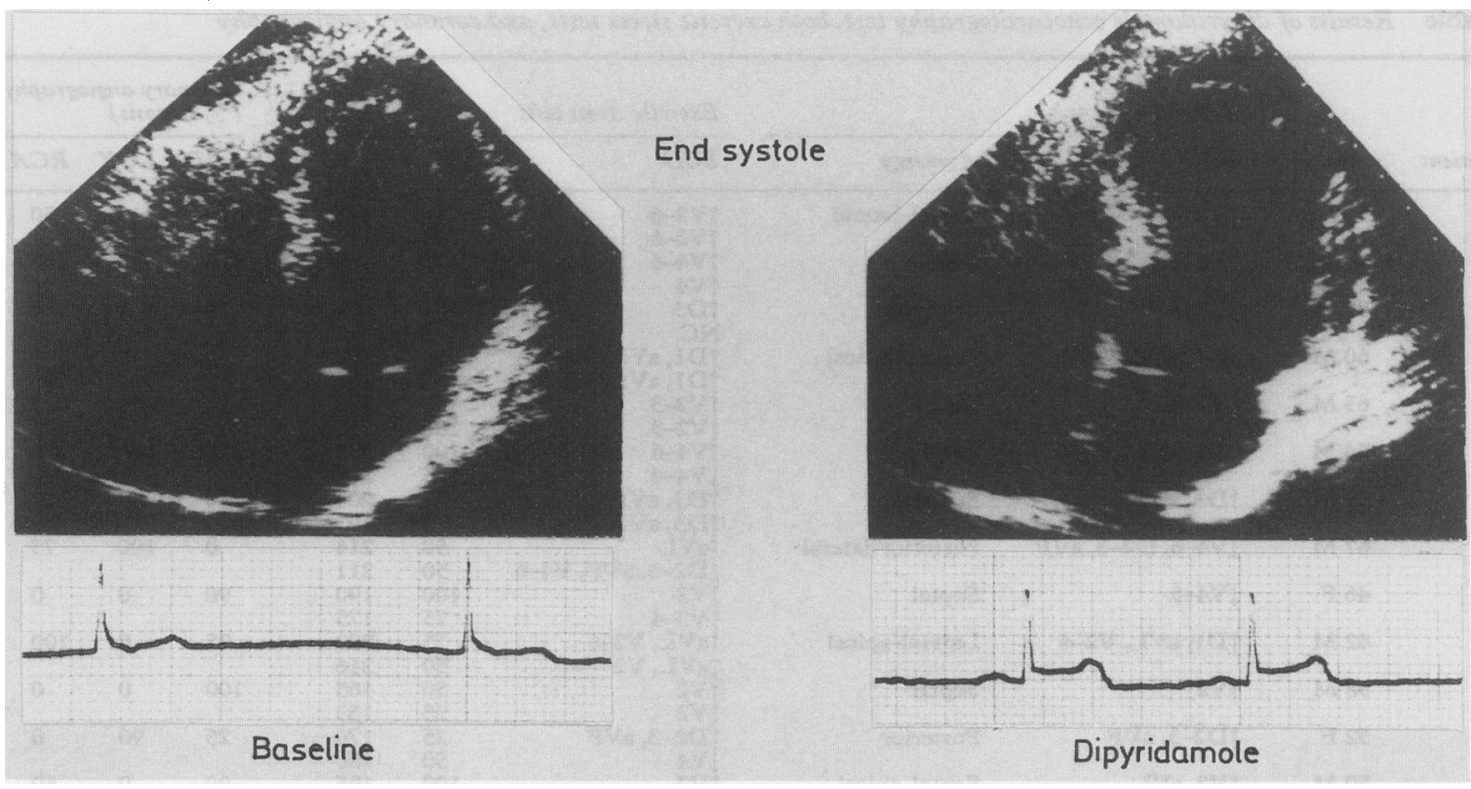

Figure Cross sectional echocardiograms recorded at rest (left) and during dipyridamole induced ischaemia (right). There was a severe basal stenosis in the left anterior descending coronary artery. Echocardiographic images were taken from the apical approach, four chamber view. They show a normally contracting apex under baseline conditions that become akinetic during dipyridamole induced ST segment elevation (V4).

segment depression) and in two out of eight patients in group 2 (both with ST depression) (p < 0.01). Exercise tolerance (expressed as the rate-pressure product) did not change substantially ( $>20 \%$ of the mean of the two tests) in 16 of the 17 patients in group 1 and in four of the eight patients in group 2 $(p<0.05)$. The repeated exercise stress test was positive in 17/19 patients with coronary disease and in one patient without coronary disease. The repeated exercise stress test was $\mathbf{8 8} \%$ accurate in identifying coronary artery disease.

\section{VARIANT ANGINA}

We defined variant angina as angina at rest (assessed by two days of monitoring on either the coronary care unit or by Holter) or after ergometrine provocation that was associated with ST segment elevation. Ergometrine testing was performed in three patients; two of them had a positive test. Variant angina was present in eight of 17 patients in group 1 and in seven of the eight patients in group 2 (difference not statistically significant). None of the patients was in an active phase of the disease ( $>$ five attacks per day). In patients with angina at rest the average number of attacks per patient per day was 2.1 for group 1 and 2.5 for group 2.

\section{Discussion}

The coronary anatomy underlying effort induced ST segment elevation was identified by the dipyridamole echocardiography test and by the repeated exercise stress test but not by a single exercise stress test or a history of variant angina.

The induction of myocardial ischaemia by the dipyridamole test combined with simultaneous monitoring by 12 lead electrocardiography and cross sectional echocardiography gives useful information. ${ }^{1011}$ The echocardiographic criterion of ischaemia is much more specific and probably more sensitive than electrocardiography. ${ }^{11}$ Furthermore, ultrasound imaging permits the site and extent of the ischaemic zone to be identified; these are not reliably shown by the electrocardiogram. ${ }^{11}$ But dipyridamole induced ST segment elevation is a more specific marker of ischaemia than ST segment depression, and in the highly selected population in this study we found that it was as good as echocardiography in identifying patients with clinically important coronary artery disease.

COMPARISON WITH PREVIOUS STUDIES

There is debate about the short term reproducibility 
of the exercise stress test in patients with effort induced ST segment elevation. De Servi et al and Brunelli et al showed a variable exercise threshold and multiple electrocardiographic patterns in patients with documented vasospastic angina undergoing repeat exercise stress testing. ${ }^{89}$ Yasue et al in a study of 13 patients with variant angina, also found poor reproducibility for ST segment elevation on effort in 11 patients (five of them had $<70 \%$ coronary stenosis). ${ }^{7}$

In contrast, Specchia et al found reproducible ST segment elevation in four patients with variant angina. Coronary arteriography showed insignificant $(<70 \%)$ coronary lesions in three of them and a $75 \%$ stenosis in the other patients. ${ }^{12}$ Waters et al also reported reproducible ST segment elevation in patients with variant angina and absent or mild $(<50 \%)$ coronary artery disease. ${ }^{13}$ These "discrepancies" may not be real because the reproducibility of a test is mainly a function of the activity of the vasospastic disease (with vasospasm being more easily elicited on effort if patients are in a more active phase of the disease).$^{14}$ Variant angina is cyclical and clinical observations and laboratory findings depend on the phase in the disease process and on treatment. ${ }^{13}$ All four patients studied by Specchia et $a l^{22}$ had multiple spontaneous episodes of ST segment elevation at rest; five of the seven patients studied by Waters $e t \mathrm{al}^{\mathrm{l}^{4}}$ had a spontaneous attack during the coronary angiography, without any provocative stimulus, indicating that they were in an active phase of the disease.

Though we agree that the cyclical nature of the disease must influence the results of screening it cannot explain the findings of our own study. Patients with dipyridamole induced ST segment elevation had more reproducible findings in the repeated exercise stress test, though they were in a less active phase of the disease than patients with negative dipyridamole echocardiography test-the average number of attacks per patient per day was lower in this group. These data draw attention to another fundamental factor that determines the short term reproducibility of the exercise stress test-the underlying organic coronary disease. Active coronary vasospasm is not the only pathogenetic mechanism of exercise induced ST segment elevation, and a severe stenosis can cause ST segment elevation on effort $^{15}$ or after dipyridamole ${ }^{1}$ through a purely haemodynamic (non-vasospastic) effect. ${ }^{16}$ In this event, because effort induced ST segment elevation is caused by organic factors it is not surprising that the electrocardiographic pattern is consistent in repeated exercise stress tests.

In patients in group 2, effort induced ST segment elevation was probably caused by vasospasm-the second exercise stress test was almost always the least abnormal. This is probably because of the inclusion/ exclusion criteria of this study. All patients had ST segment elevation in the first exercise stress test and none had more than five anginal attacks per day. Under these conditions the second exercise stress test is more likely to give better results than the first one; also patients will be less anxious (a possible contributing factor to spasm) about a repeat test.

\section{CLINICAL IMPLICATIONS}

In the absence of previous myocardial infarction, elevation of the ST segment with exercise is considered to be specific for coronary spasm by some ${ }^{45}$ and a reliable marker of very severe fixed coronary artery disease by others. ${ }^{151718}$ Both these views may need to be amended in the light of our findings. A negative repeated exercise stress test with a negative high dose dipyridamole echocardiography test strongly suggest that no haemodynamically significant stenosis is present, ${ }^{11} 19$ even if superimposed functional factors may transiently impair the exercise capacity. ${ }^{20}$ Conversely, a dipyridamole induced ST segment elevation must imply the presence of physiologically, as well as anatomically, severe coronary stenosis, which probably also limits exercise capacity.

Dr E Picano is the recipient of the Associazione Ricerca Medica research fellowship for ultrasonic diagnosis of atherosclerosis. Dr G A Klassen is from Dalhousie University, Halifax, Nova Scotia, Canada, and is presently spending a sabbatical year at the Instituto di Fisiologia Clinica del CNR.

\section{References}

1 Picano E, Masini M, Distante A, et al. Dipyridamoleechocardiography test in patients with exerciseinduced ST segment elevation. Am $J$ Cardiol 1986;57:765-70.

2 Brown BG, Bolson EL, Dodge HT. Dynamic mechanisms in human coronary stenosis. Circulation 1984;70:917-22.

3 Picano E, Morales MA, Distante A, et al. Dipyridamole-echocardiography test in angina at rest: non invasive assessment of coronary stenosis underlying spasm. Am Heart $J$ 1986;111:688-72.

4 De Servi S, Falcone C, Gavazzi A, et al. The exercise test in variant angina: results in 114 patients. Circulation 1981;64:684-8.

5 Waters DD, Chaitman BR, Bourassa MG, Tubau JF. Clinical and angiographic correlates of exerciseinduced ST segment elevation. Increased detection with multiple ECG leads. Circulation 1980;61: 286-96.

6 Waters DD, McCans JL, Crean PA. Serial exercise testing in patients with effort angina: variable 
tolerance, fixed threshold. J Am Coll Cardiol 1985;6:1011-5.

7 Yasue $\mathbf{H}$, Omote S, Takizawa A, Nagao M, Miwa K, Tanaka S. Circadian variation of exercise capacity in patients with Prinzmetal's variant angina: role of exercise-induced coronary arterial spasm. Circulation 1979;59:938-48.

8 De Servi S, Specchia G. Falcone C, et al. Variable threshold exertional angina in patients with transient vasospastic myocardial ischemia. Repeat exercise test results and therapeutic implications. Am J Cardiol 1983;51:397-402.

9 Brunelli C, Lazzari M, Simonetti I, L'Abbate A, Maseri A. Variable threshold of exertional angina: a clue to a vasospastic component. Eur Heart J 1981;2:155-61.

10 Picano E, Distante A, Masini M, Morales MA, Lattanzi F, L'Abbate A. Dipyridamole-echocardiography test in effort angina pectoris. Am J Cardiol 1985;56:452-6.

11 Picano E, Lattanzi F, Masini M, Distante A, L'Abbate A. High dose dipyridamole-echocardiography test in effort angina pectoris. J Am Coll Cardiol 1986;8: 848-54.

12 Specchia G, de Servi S, Falcone C, et al. Coronary arterial spasm as a cause of exercise-induced ST segment elevation in patients with variant angina. Circulation 1979;59:948-54.

13 Waters DD, Szlachcic J, Bourassa MG, Scholl JM, Theroux P. Exercise testing in patients with var- iant angina: results, correlation with clinical and angiographic features and prognostic significance. $C$. Circulation 1982;65:265-71.

14 Waters DD, Chaitman BR, Dupras G, Theroux $P_{5}$, Mizgala HF. Coronary artery spasm during exercise in patients with variant angina. Circulation 1979;59:580-5.

15 Dunn R, Freedman B, Kelly DT, Bailey IK, McLaughlin A. A predictor of anterior myocardialo ischemia and left anterior descending coronary artery ${ }^{2}$ disease. Circulation 1981;63:1357-63.

16 Ganz W. Coronary spasm in myocardial infarction: fact or fiction? Circulation 1981;63:487-9.

17 Fortuin NJ, Friesinger GC. Exercise-induced ST segment elevation. Clinical, electrocardiographic and arteriographic studies in twelve patients. Am J Medo 1970;49:459-68.

18 Mark DB, Pryor DB, Hlatky MA, Lee KL, Harrel FE, i Califf RM. Exercise ST elevation: a reliable guide to coronary anatomy [Abstract]. J Am Coll Cardiolo 1986;7:163A.

19 Picano E, Simonetti I, Masini M, et al. Transient myocardial dysfunction during pharmacologice vasodilation as an index of reduced coronary reserve:O a coronary hemodynamic and echocardiographic $\frac{\mathbb{D}}{-}$ study. J Am Coll Cardiol 1986;8:84-90.

20 Maseri A, Chierchia S, Kaski JC. Mixed angina价 pectoris. Am J Cardiol 1985;56:30E-3E. 